\title{
Advice on air travel for patients with chronic respiratory conditions
}

\author{
Dale Lien MD \\ Associate Professor, Division of Pulmonary Medicine \\ University of Alberta, Edmonton, Alberta
}

The development of commercial air travel has allowed safe and convenient travel to almost all parts of the world. For patients with chronic respiratory conditions, current proactive attitudes, coupled with advances in drug therapy, oxygen delivery systems and rehabilitation programs, have resulted in many more of us being able to experience the freedom of air travel. When planning for commercial air travel, patients with chronic respiratory disorders must be aware that they are subject to more potential difficulties. However, proper understanding of the problems that may be encountered, coupled with advanced planning and preparation, should minimize any problems.

\section{What are the potential problems that I may encounter?}

All air travellers are subject to many stresses including fatigue, sleep deprivation, disruption of normal schedules and the logistics of unexpected delays. Patients with chronic respiratory conditions are not only subject to these usual problems but must also be aware of the additional problems specific to their condition that may add to their difficulties. If you are affected by a chronic respiratory condition, the following list will highlight some of the problems that you need to anticipate and discuss with your doctor well in advance of your flight.

- Due to the effects of increased altitude on blood oxygen levels (see below), it may be necessary to increase oxygen flows if you are on oxygen supplementation. If you are not presently taking oxygen, it may be necessary to arrange for oxygen supplementation.

- Medications need to be reviewed so you can decide if a change in dosage or additional treatment is required.

- Air travel induces physical stresses and fatigue. Attendance at a local rehabilitation program, where you can learn energy conservation techniques and improve fitness, may be helpful. The use of a stick or walker, or arranging for a wheelchair, should be considered.

- Possible disruptions to your usual schedules for meals and drugs need to be foreseen.

- Alcohol and caffeine consumption in-flight have a number of adverse effects and should be avoided.

- Dehydration (lack of body fluids) is common during air travel; consider taking your own drinks to supplement those available on the flight. Also, your travel agent can easily order a special meal if necessary. 
- Increased costs of travel, including the cost of ground transportation, are worth reviewing with your travel agent.

- Making arrangements for a travel companion may be necessary.

- The logistics of transporting respiratory equipment and oxygen should be worked out before take-off.

- Making arrangements for in-flight oxygen and paying the high cost for this service may lead to difficulties. Information regarding the cost of, and policies on, in-flight oxygen are readily available from the airline.

\section{What is the effect of air travel on my blood oxygen level?}

The routine cruising altitudes of commercial jet aircraft vary from 6700 to 13,400 metres above sea level. Although the cabins are partially pressurized, cabin pressures are not maintained at ground level equivalents because of concerns with operating efficiency, structural integrity and cost effectiveness. The maximum amount of cabin pressurization capacity is usually fixed on a given aircraft, and is generally greater in newer aircraft that were designed to fly at higher altitudes. The cabins are usually pressurized to an equivalent of about 1700 to 2000 metres. Although the proportion of oxygen in the surrounding air always remains constant at approximately $21 \%$, the lower barometric pressure results in lower oxygen pressures in the surrounding air. Therefore, in all passengers, oxygen levels in the bloodstream will become lower than at ground level. For travellers with normal lung function, this is not a problem, but for those who have respiratory impairment with borderline or low oxygen levels on the ground, there is a potential (while flying) for dangerously low levels of oxygen to be present in the blood. This can be enough to make you feel more short of breath, dizzy and fatigued.

\section{What do I need to do?}

Many potential problems can be overcome by proper planning and prevention. Specific suggestions include the following:

- Book flights early. Try to arrange flights that provide the least duration of travel and minimize layovers. Avoid travel times that disrupt your schedule, such as nighttime flying.

- Visit your physician well in advance to ensure that your lung condition is stable, and to see if you require oxygen supplementation or an increase in oxygen flow rate in-flight. It is usually necessary to increase oxygen flow rates by 1 to $3 \mathrm{~L} / \mathrm{min}$ in patients already on oxygen.

- Contact your airline well in advance to find out what their policy is on in-flight oxygen. Some airlines will allow you to bring your own oxygen equipment while others insist on using their own. Also, the cost may vary significantly from airline to airline. Some overseas airlines still allow smoking; you will need to sit as far away as possible from smoking sections.

- Contact your respiratory supply company well in advance to request their assistance in arranging for oxygen supplies. They can help to arrange for oxygen when you arrive at your destination by putting you in touch with a local company. In addition, it may be your responsibility to arrange for oxygen during any layovers. Your respiratory therapist can help you with any calculations, arrangements and extra equipment.

- Ensure that you are well rested and that your schedule is disrupted as little as possible. Avoid alcohol consumption, dehydration and overeating because these may aggravate your symptoms.

- Some travel agencies specialize in arranging travel for people with physical impairments and these agencies may be an invaluable source of help.

- Ensure that you have adequate medical insurance coverage. 


\section{Role of the airline}

Air carriers have recognized that they have a responsibility to assist the physically impaired, and have accepted the fact that in-flight oxygen therapy is safe and manageable. However, there is still not a uniform policy, and each airline has its own requirements. Most airlines require advance bookings, assessment by a qualified physician and consideration of individual cases by their own medical department. However, a national Canadian policy may soon be developed.

\section{Additional resources}

A helpful and easy-to-read booklet has been written by Phil Peterson, who has had a lot of first-hand knowledge of travelling with severe chronic obstructive pulmonary disease:

- Peterson P. Good If Not Great Living With Lung Disease, edited by Sheree B Watson (1999). Raven Publishers Inc, Charlotte. PO Box 242275 Charlotte, North Carolina 28224-9798, USA. ISBN 0962172642; 116 pages. Telephone 1-888-552-2577, e-mail oxygenbook@aol.com.

The following article also has useful information:

- Lien D, Turner M. Recommendations for patients with chronic respiratory disease considering air travel: A statement from the Canadian Thoracic Society. Can Respir J 1998;5:95-100.

If you have access to the internet, the following web sites are worth looking at:

- Canadian Lung Association - www.lung.ca;

- Respiratory Therapy Society of Ontario - www.rtso.org; and

- American Lung Association - www.lungusa.org.

This information should not be used as a substitute for the medical care and advice of your physician. There may be variations in treatment that your physician may recommend based on individual facts and circumstances. This information may be reproduced without permission and shared with patients and their families. 


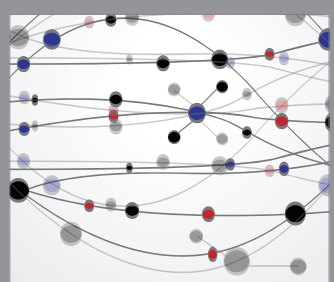

The Scientific World Journal
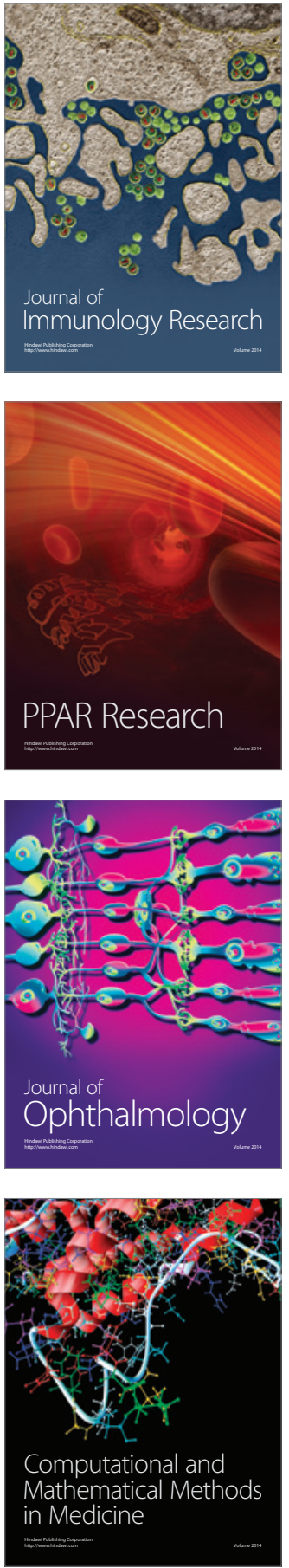

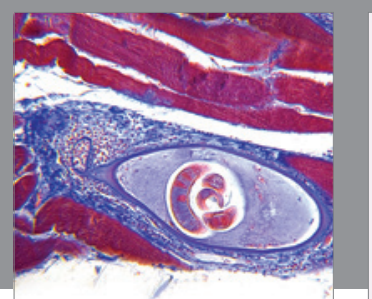

Gastroenterology Research and Practice

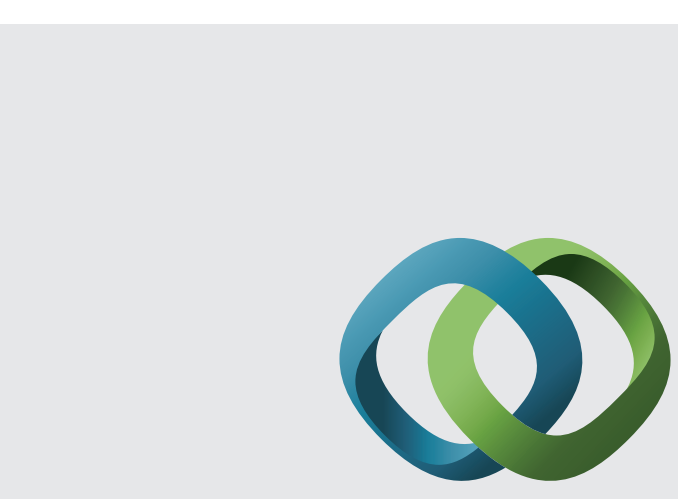

\section{Hindawi}

Submit your manuscripts at

http://www.hindawi.com
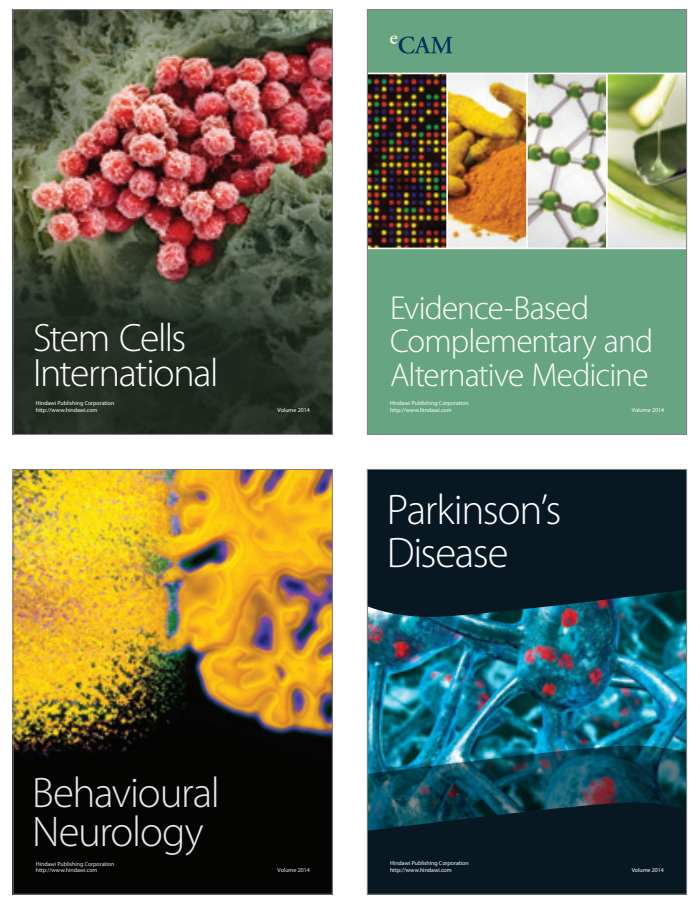
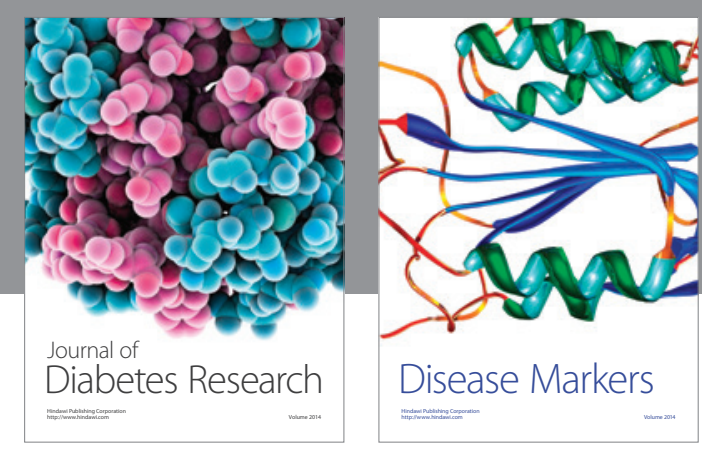

Disease Markers
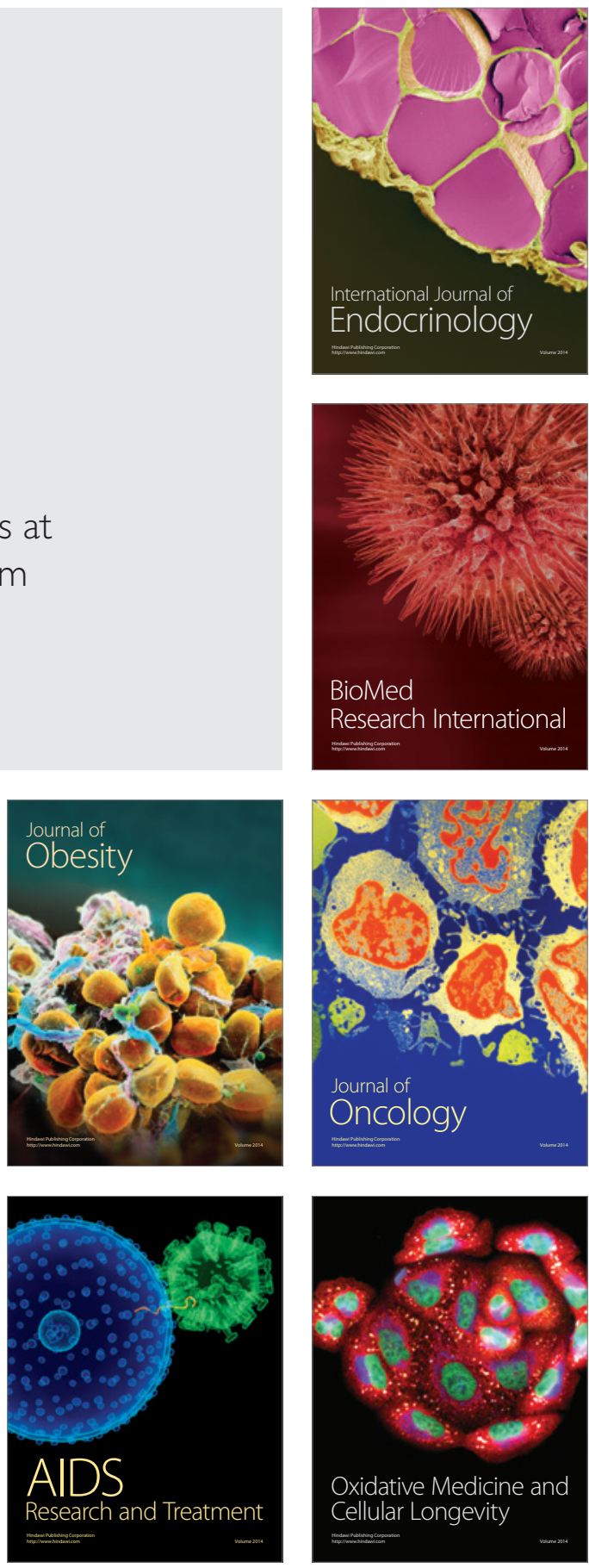